



\section{Economic prospects for large-scale seaweed cultivation in the North Sea}

Sander van den Burg

With support from Cito Wakenge and Petra Berkhout

This research project was carried out by Wageningen Economic Research at the request of and with funding from the North Sea Farm (NSF) and the Ministry of Economic Affairs for the purposes of Policy Support Research Theme 'Maatschappelijk Innovatieprogramma PROSEAWEED' (project number BO-47-001-001)

Wageningen Economic Research

Wageningen, February 2019

MEMORANDUM

2019-012 
Sander van den Burg, 2019. Economic prospects for large-scale seaweed cultivation in the North Sea. Wageningen, Wageningen Economic Research, Memorandum 2019-012. 20 pp.; 6 fig.; 5 tab.; 10 ref.

The North Sea Farm Foundation pioneers seaweed cultivation in the North Sea. This project addresses the economic prospects of up-scaled production of seaweed, looking at production costs only. Scenarios for future large-scale seaweed production are formulated and evaluated using the EnAlgae economic model. Additionally, Monte Carlo analysis is performed. Based on the findings, we conclude that a significant cost reduction seems possible, with expected cost prices down to $€ 1,200$ per ton DM. If all goes well, relatively low-value markets such as the alginate market are within reach. More realistically, a mix of low- and medium-value markets is needed to cover the costs of seaweed production in the North Sea. Current developments show that these markets exist; especially in the food market where seaweeds can be promoted as organic, sustainable and fair trade.

Key words: seaweed, aquaculture, economic scenarios

This report can be downloaded for free at https://doi.org/10.18174/470257 or at www.wur.eu/economic-research (under Wageningen Economic Research publications).

(C) 2019 Wageningen Economic Research

P.O. Box 29703, 2502 LS The Hague, The Netherlands, T +31 (0)70 33583 30,

E communications.ssg@wur.nl, http://www.wur.eu/economic-research. Wageningen Economic Research is part of Wageningen University \& Research.

\section{(cc) BY-NC}

For its reports, Wageningen Economic Research utilises a Creative Commons Attributions 3.0 Netherlands license.

(c) Wageningen Economic Research, part of Stichting Wageningen Research, 2019

The user may reproduce, distribute and share this work and make derivative works from it. Material by third parties which is used in the work and which are subject to intellectual property rights may not be used without prior permission from the relevant third party. The user must attribute the work by stating the name indicated by the author or licensor but may not do this in such a way as to create the impression that the author/licensor endorses the use of the work or the work of the user. The user may not use the work for commercial purposes.

Wageningen Economic Research accepts no liability for any damage resulting from the use of the results of this study or the application of the advice contained in it.

Wageningen Economic Research is ISO 9001:2008 certified.

Wageningen Economic Research Memorandum 2019-012 | Project code 2282700383

Cover photo: Shutterstock 


\section{Contents}

1

Introduction $\quad 5$

1.1 Research questions $\quad 5$

2

$\begin{array}{ll}\text { Methodology } & 6\end{array}$

2.1 Model Selection $\quad 6$

$\begin{array}{lll}2.2 \text { Scenarios } & 7\end{array}$

2.3 Monte Carlo analysis $\quad 8$

3

$\begin{array}{ll}\text { Results } & 9\end{array}$

3.1 Base case and upscaling scenario $\quad 9$

3.2 Sensitivity to individual parameters 10

3.2.1 Upscaling 10

3.2.2 Reducing the costs of plant material 10

3.2.3 Increasing the yield 10

3.2.4 Increasing yield under lower cost of plant material $\quad 10$

3.2.5 Combined use $\quad 12$

3.3 Multidimensional scenarios 12

$\begin{array}{ll}3.4 & \text { Likelihood of future costs of seaweed production } \\ \end{array}$

$4 \quad$ Reflection on the World Bank report $\quad 14$

4.1 A skewed comparison with other countries 14

$\begin{array}{lll}4.2 & \text { Reflection from a food systems perspective } & 15\end{array}$

$\begin{array}{llr}5 & \text { Conclusions } & 17\end{array}$

5.1 Indications for future research on and development of seaweed cultivation 17

5.2 Improving economic models for seaweed cultivation $\quad 18$

$\begin{array}{lr}\text { References and websites } & 19\end{array}$ 



\section{Introduction}

The North Sea Farm Foundation pioneers seaweed cultivation in the Dutch Exclusive Economic Zone of the North Sea. A test site is up and running to demonstrate the technological and biological feasibility of offshore seaweed production.

An economic assessment of the expected future costs of seaweed production is needed. However, information concerning the costs of seaweed production in the North sea is scarce, as it is for other waters in the northern hemisphere. A few studies have calculated the expected production costs based on expert judgment (see e.g. van den Burg et al. 2016). Bak et al. (2018) calculated the costs of seaweed production near the Faroes based on real-life experiences, but we must be careful extrapolating their results due to differences in climate and ocean conditions. Most notably, the constant seawater temperature near the Faroes allows for multiple harvests per year.

\subsection{Research questions}

This project addresses the economic prospects of up-scaled production of seaweed in the North Sea, looking at production costs only. ${ }^{1}$ Based on future scenarios, the project examines whether upscaling could reduce the production costs. The main research question is: "What is the effect of upscaling production on the cost of producing seaweeds in the North Sea?"

The study examines the impact of various changes (upscaling, lower costs of plant material, changes in yield and the combined use of facilities) on total production costs.

The main research question is broken down into a number of sub-questions:

- What are the expected production costs and what are the most important cost factors? (section 3.1)

- How do the costs of seaweed production change under different scenarios? (sections 3.2-3.3)

- What is the influence of uncertainty on the production costs? (section 3.4)

- How do these production costs compare to the production costs presented in a recent World Bank report? (section 4)

- What are the indications for future research on and development of seaweed cultivation? (section 5.1)

- How can economic models be further improved to give insight into the economic feasibility of seaweed cultivation? (section 5.2)

\footnotetext{
${ }^{1}$ Detailed and reliable information on the value of seaweeds in various European markets is currently unavailable, although it is being studied in various project, including the H2020 project GENIALG.
} 


\section{Methodology}

\section{$2.1 \quad$ Model Selection}

After a comprehensive review of literature on the costs of offshore seaweed and the available economic models, it was concluded that the EnAlgae Model (output WP2A7.06 - available online ${ }^{2}$ ) is the most suitable model. The EnAlgae project was a Strategic Initiative in the INTERREG IVB North West Europe programme, with activities taking place between late 2011 and December 2015. It brought together 19 partners and 14 observers across 7 EU Member States with the aim of developing sustainable technologies for algal biomass production and quantifying the scope for commercial algae production for energy and other products in northwest Europe.

In EnAlgae, a best practices guide for seaweed cultivation was developed, as was a detailed economic model that allows for the calculation of the costs of seaweed production. This model is based on input from various seaweed farmers throughout Europe, thus providing an empirically validated model. It can be used to calculate the costs of seaweed production under a base case and under various scenarios.

For all scenarios, we assume that Saccharina latissima is produced offshore, using a system with longlines and V-droppers. It is also assumed that the plant material is sourced from a third party (i.e. not produced in an own hatchery). The model was run various times, with different input parameters to test sensitivity to changes in input parameters.

The costs of offshore mussel production derived from the MARIBE project are presented in van den Burg et al. (2017). Whilst the analysis in this project focusses on seaweeds, we also test scenarios in which the co-use of the infrastructure is foreseen.

More detailed economic models for the micro-economic analysis of the cost of seaweed cultivation are being developed in the GENIALG project, but useable results will not be available in time. In this report, we reflect on the requirements of economic models and provide recommendations for further developing an economic model to assess the economic feasibility of seaweed cultivation and use (section 4.2).

2 http://www.enalgae.eu/getfile.php?type=site_documents\&id=WP2A7.06\%20 model\%20economics\%20 macroalgae\%20v18.0 2.15.xlsx 


\subsection{Scenarios}

The table below gives an overview of the different scenarios evaluated in this study. A differentiation is made between one-dimensional scenarios - in which only one input parameter changes - and multidimensional scenarios, in which various input parameters change.

Table 1 Characterisation of the scenarios

\begin{tabular}{|c|c|c|c|c|c|}
\hline & Change foreseen & $\begin{array}{l}\text { No. of units }{ }^{1} \text { and } \\
\text { staff }\end{array}$ & $\begin{array}{l}\text { Cost seeded } \\
\text { line }(\boldsymbol{C} / \mathrm{m})\end{array}$ & $\begin{array}{l}\text { Yield } \\
\text { (fresh weight/m } \\
\text { dropper line) }\end{array}$ & Combined use \\
\hline \multirow[t]{3}{*}{ One-dimensional } & Upscaling & $\begin{array}{l}1,000 / 8 \text { staff } \\
2,000 / 16 \text { staff } \\
3,000 \text { / } 24 \text { staff } \\
4,000 \text { / } 32 \text { staff } \\
5,000 \text { / } 40 \text { staff }\end{array}$ & $€ 5 / m$ & $10 \mathrm{~kg}$ & No \\
\hline & $\begin{array}{l}\text { Reduce costs plant } \\
\text { material }\end{array}$ & 1,000 units & $\begin{array}{l}€ 5 \\
€ 4 \\
€ 3 \\
€ 2 \\
€ 1\end{array}$ & $10 \mathrm{~kg}$ & No \\
\hline & Combined use & 1,000 units & $€ 5 / \mathrm{m}$ & $10 \mathrm{~kg}$ & $\begin{array}{l}\text { Yes, sharing } \\
\text { capital costs } \\
(50 \%)\end{array}$ \\
\hline Multi-dimensional & $\begin{array}{l}\text { Increase yield and } \\
\text { lower cost of plant } \\
\text { material }\end{array}$ & 1,000 units & $€ 1 / \mathrm{m}$ & $\begin{array}{l}10 \mathrm{~kg} \\
15 \mathrm{~kg} \\
20 \mathrm{~kg} \\
25 \mathrm{~kg} \\
30 \mathrm{~kg}\end{array}$ & No \\
\hline
\end{tabular}

1) A unit is defined as one anchored longline with dropper lines. 


\subsection{Monte Carlo analysis}

A Monte Carlo analysis was performed to illustrate the range of expected cost prices of seaweed production. Monte Carlo simulation is used for better decision making under uncertainty. In such an analysis, it is assumed that the expected value of all cost factors is normally distributed, with a mean (the estimated value) and uncertainty (expressed as standard deviation).

The base case scenario presented in section 3.1 provided input parameters for this analysis (see table 2). Based on expert knowledge, we assumed plausible future costs and quantified uncertainty. This constitutes input parameters for the analysis. A minimum value was added to prevent the model from assuming negative costs.

Table 2 Input parameters for the Monte Carlo analysis

\begin{tabular}{|c|c|c|c|c|}
\hline & $\begin{array}{l}\text { Production costs in the } \\
\text { base case ( }(\mathcal{k} / \mathrm{kg} F W)\end{array}$ & Expected & SD & Minimum \\
\hline Plant material & 0.5 & 0.20 & $15 \%$ & 0.1 \\
\hline Labour & 0.080 & 0.060 & $10 \%$ & 0.01 \\
\hline Capital goods & 0.063 & 0.050 & $10 \%$ & 0.01 \\
\hline
\end{tabular}

Note that the expected values per cost factor do not necessarily present the most optimistic values worked with in the scenarios. Different standard deviations were chosen to reflect the uncertainty; the future costs of plant material (stemming from a sector that is still in development) are more uncertain than the costs of boat hire (a well-developed sector). 


\section{Results}

\subsection{Base case and upscaling scenario}

In this scenario, Saccharina latissima is cultivated offshore in the North Sea, using a system of longlines and V-droppers. Plant material is sourced from another company and the cultivation system is based on the direct seeding of gametophytes. There is no combined use of facilities with other sectors.

The longlines are $110 \mathrm{~m}$ long and there are $270 \mathrm{~m}$ of $\mathrm{V}$-droppers per longline. By and large, this resembles the technical design by the North Sea Farm Foundation. Seeded strings are attached to the dropper rope ( $1 \mathrm{~m}$ of seeded string per $1 \mathrm{~m}$ of dropper rope). The growing period is set at 20 weeks. There is no combined use of offshore facilities with other sectors. It takes 1 hour to reach the system from harbour. The lifespan of the system is by default set at 5 years, except for the long line ( 3 years) and protective clothing ( 3 years). Table 3 gives an overview of the most important input parameters.

Table 3 Input parameters for base case scenario

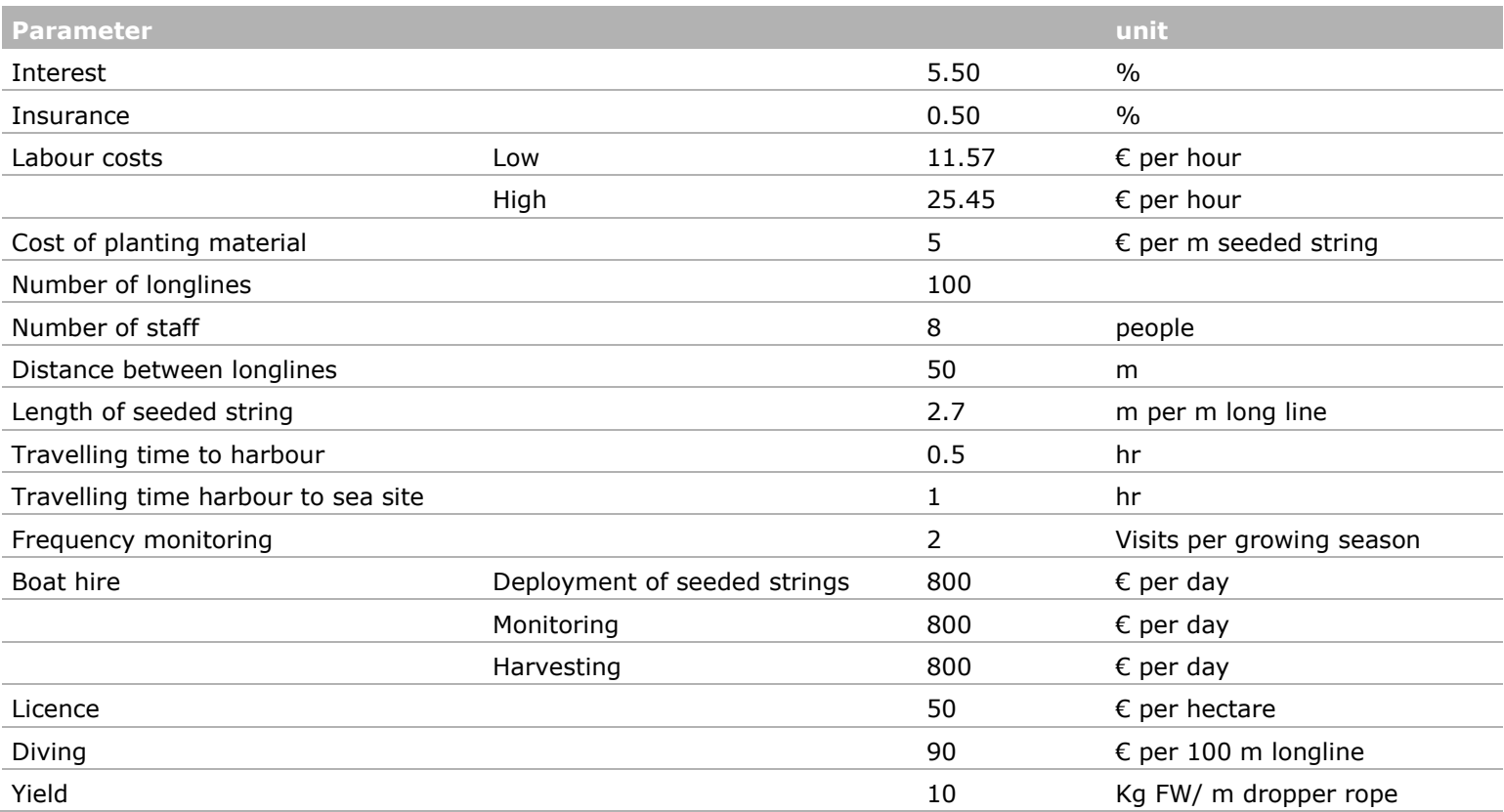

The results for the expected costs of seaweed production with 1,000 units and 8 staff members are presented in figure 1 . Important cost factors are the cost of plant material and boat hire. The effects of reducing these costs are discussed in the following sections, after an analysis of the effects of upscaling. We also address sensitivity to changes in yield and the potential effect of the co-use of facilities with mussel cultivation. 


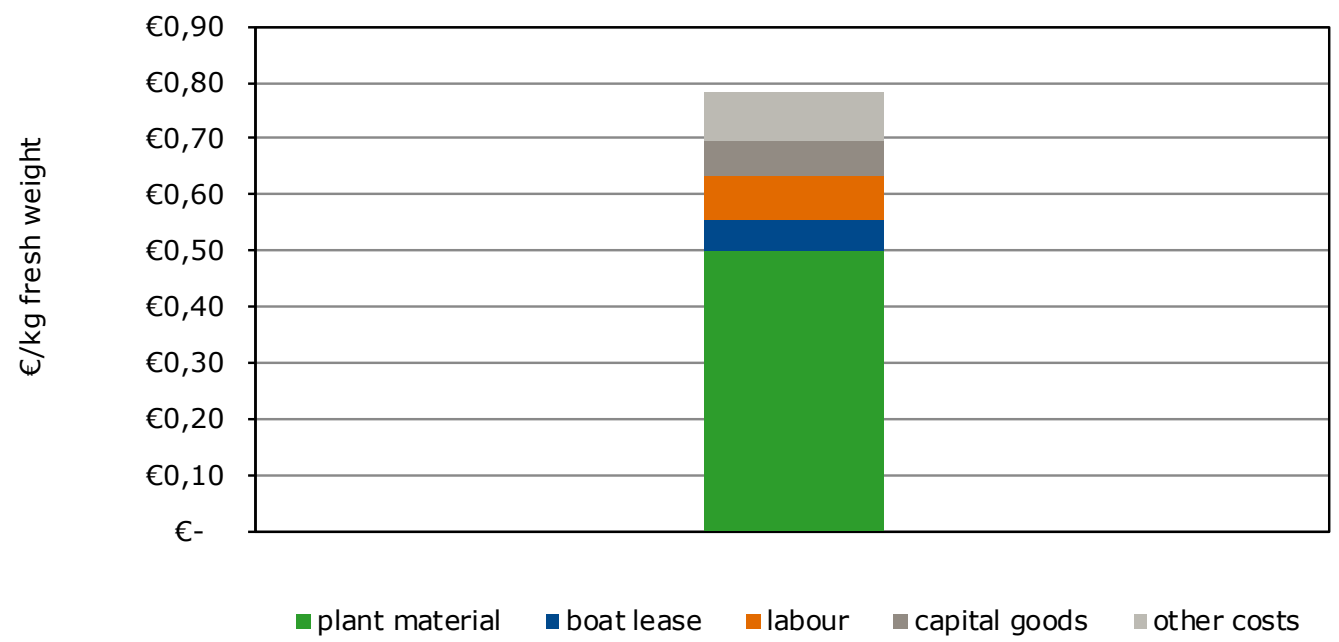

Figure 1 Costs of seaweed production under base case ( $€$ per $\mathrm{kg} F W$ )

\subsection{Sensitivity to individual parameters}

In the following tables, the effect of changes in the following parameters are described: number of units deployed, costs of plant material and yield.

\subsubsection{Upscaling}

In this scenario, the scale of production increases from the original 100 production units to 1,000 , $2,000,3,000,4,000$ and 5,000 units. Assuming that these numbers of units cannot be maintained and harvested by the original number of staff, their number is increased proportionally. The results are presented in figure $2 \mathrm{a}$ (absolute numbers) and figure $2 \mathrm{~b}$ (contribution of cost factor to total).

\subsubsection{Reducing the costs of plant material}

In this scenario, the effect of changes in cost prices of seeded string were analysed. Originally set at $€ 5$ per metre of seeded string, the effects of reducing costs to $€ 4, € 3, € 2$ and $€ 1$ per metre were analysed. The results are presented in figure $2 \mathrm{c}$ (absolute numbers) and figure $2 \mathrm{~d}$ (contribution of cost factor to total).

\subsubsection{Increasing the yield}

Under the base case scenario, the yield of seaweed is $10 \mathrm{~kg} \mathrm{FW} / \mathrm{m}$ dropper line. This scenario presents sensitivity to changes in yield, assuming 10, 15, 20, 25 and $30 \mathrm{~kg} \mathrm{FW/m} \mathrm{dropper} \mathrm{line.} \mathrm{The} \mathrm{results} \mathrm{are}$ presented in figure $2 \mathrm{e}$ (absolute numbers) and figure $2 \mathrm{f}$ (contribution of cost factor to total).

The effect of yield increase has a higher impact on the reduction of the cost of plant material, labour cost and boat hire costs, and a relatively low impact on other costs. Yield increase plays a key role in reducing the production cost.

\subsubsection{Increasing yield under lower cost of plant material}

In this scenario, the following assumption are made. It is assumed that the costs of seeded string are reduced to $€ 1$ per metre. We then assessed sensitivity to changes in yield, assuming 10, 15, 20, 25 and $30 \mathrm{~kg} \mathrm{FW} / \mathrm{m}$ dropper line. The results are presented in figure $2 \mathrm{~g}$ (absolute numbers) and figure $2 \mathrm{~h}$ (contribution of cost factor to total). 
The results of the analyses discussed above are presented in figures $2 \mathrm{a}-2 \mathrm{~h}$. The figures should be read as follows:

- On the left-hand side (figures $2 a, 2 c, 2 e, 2 g$ ), the absolute contribution of 5 cost factors to the production costs of $1 \mathrm{~kg}$ fresh weight seaweed are presented for each scenario.

- On the right-hand side (figures $2 b, 2 d, 2 f, 2 h$ ), the relative contribution of 5 cost factors to the production costs of $1 \mathrm{~kg}$ fresh weight seaweed are presented for each scenario.

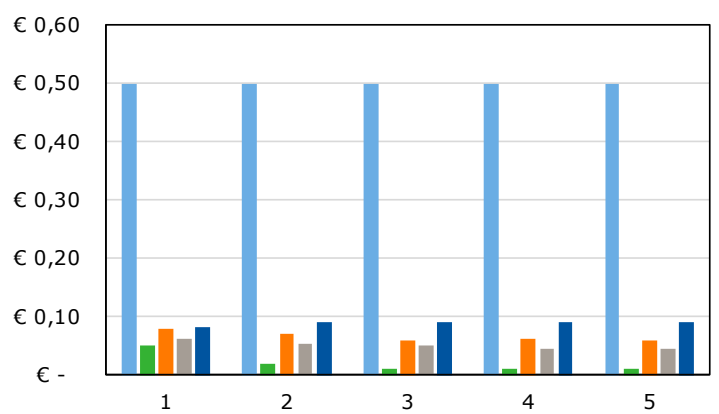

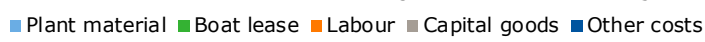

Figure 2a Upscaling

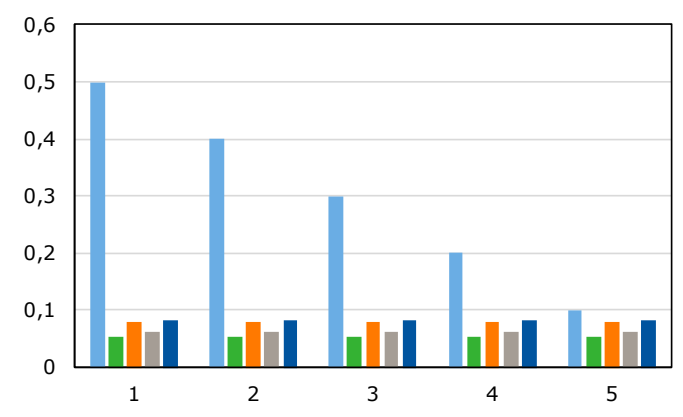

$\varpi$ Plant material $\backsim$ Boat lease $\backsim$ Labour $\backsim$ Capital goods $\backsim$ Other costs

Figure 2c Reducing costs of plant material

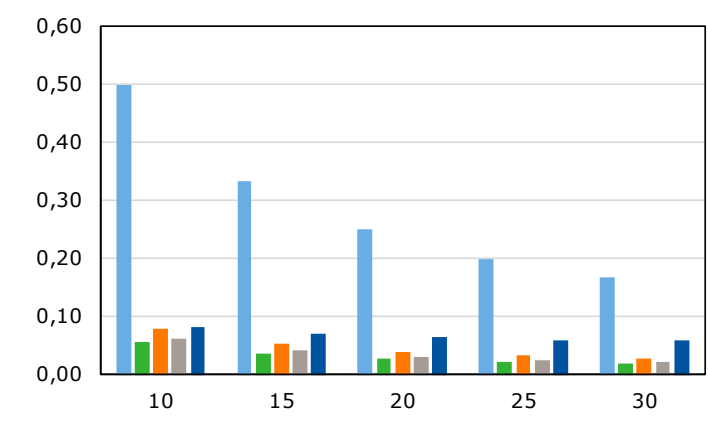

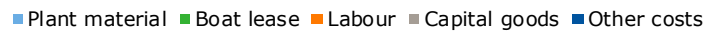

Figure 2e Increasing the yield

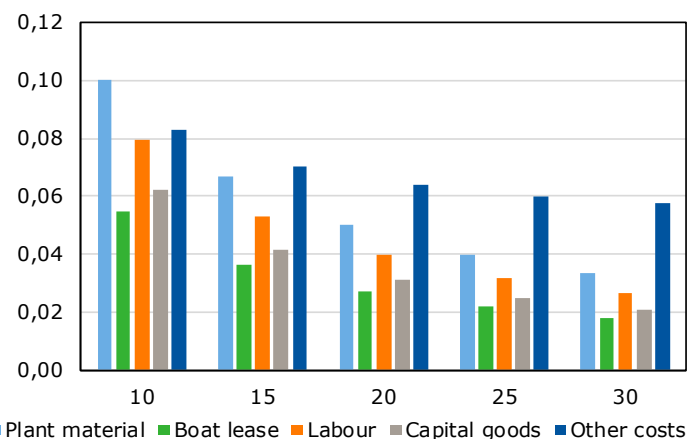

Figure $2 \mathrm{~g}$ Increasing yield, with lower costs plant material

Figure 2 Results of scenario analysis

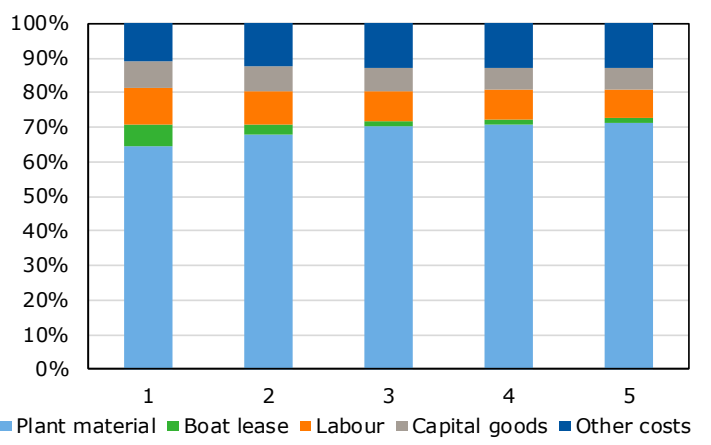

Figure $2 \boldsymbol{b} \quad$ Upscaling

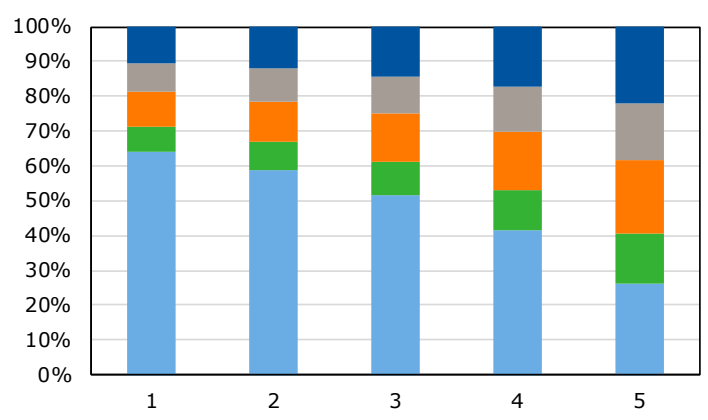

$\backsim$ Plant material $\backsim$ Boat lease $\backsim$ Labour $\backsim$ Capital goods $\backsim$ Other costs

Figure 2d Reducing costs of plant material

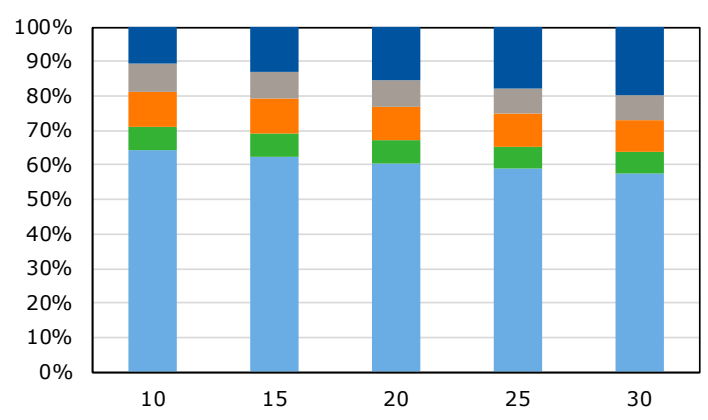

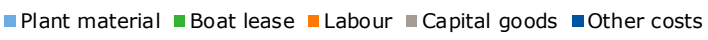

Figure $2 f$ Increasing the yield

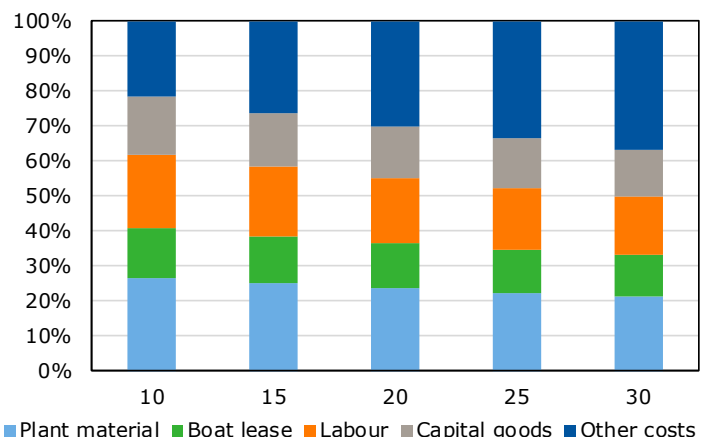

Figure $2 \boldsymbol{h}$ Increasing yield, with lower costs plant material 


\subsubsection{Combined use}

In this scenario, it is assumed that the infrastructure of the seaweed farm is also used for other activities (i.e. growing mussels). The fraction of capital costs allocated to seaweed farming is set at $50 \%$. Total calculated cost price of seaweed is $€ 0.74$ per $\mathrm{kg} F W$. A breakdown of costs is provided in figure 3.

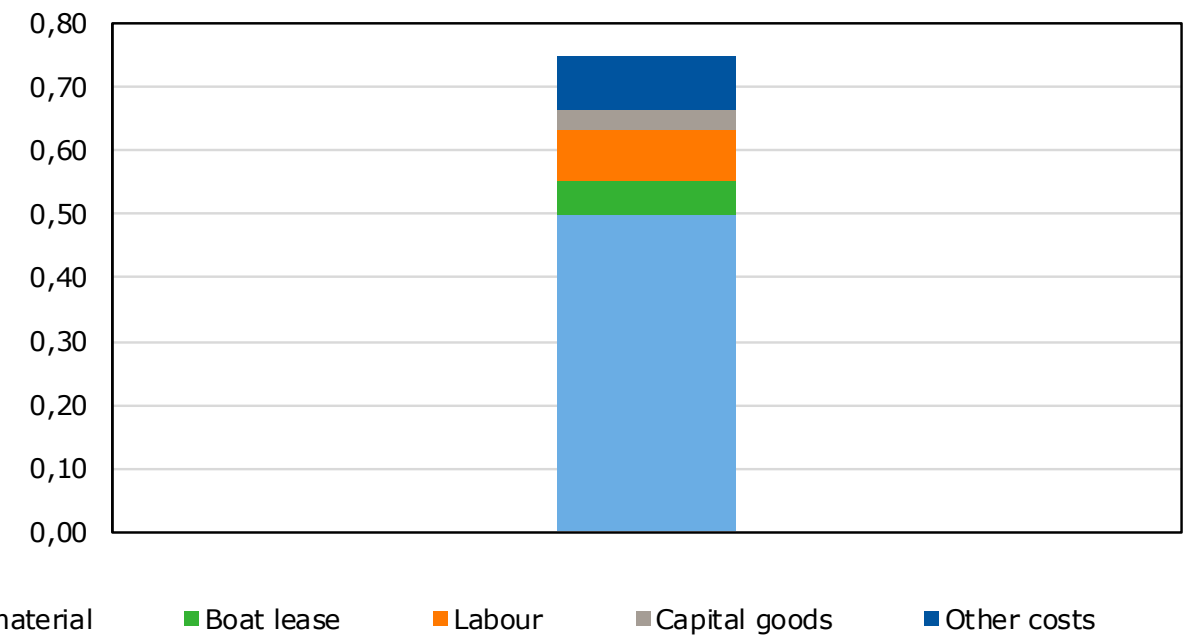

Figure 3 Breakdown of costs in a combined use scenario

\subsection{Multidimensional scenarios}

Below we present the analysis of multiple changes in input parameters. In the first scenario, it is assumed that the cost of seeded string is reduced $(€ 1)$, a yield of $20 \mathrm{~kg} \mathrm{FW} / \mathrm{m}$ is realised and the cost of boat hire is reduced to $€ 400$ per day, for all types of boats. The calculated cost price of seaweed is then $€ 0.20$ per kg FW. A breakdown into cost factors is provided in figure $4 \mathrm{a}$. Reducing the cost of boat hire while increasing yield at a reduced cost of planting material showed a positive effect on overall production cost. Looking at individual costs, 'other costs' make up the largest part of the total costs.

In the second scenario, the combined use of infrastructure is foreseen, with $50 \%$ of capital costs allocated to a different sector. Furthermore, it is assumed that the cost of seeded string is reduced $(€ 1)$, that a yield of $20 \mathrm{~kg} \mathrm{FW} / \mathrm{m}$ is realised and that the cost of boat hire is reduced to $€ 400$ per day, for all types of boats. The calculated total cost price is $€ 0.18$ per $\mathrm{kg} F W$. A breakdown into cost factors is provided in figure $4 \mathrm{~b}$. Co-use by seaweed and mussel producers with reduced cost of boat hire and increased yield at lower cost of plant material showed the most positive effect on overall cost reduction. 


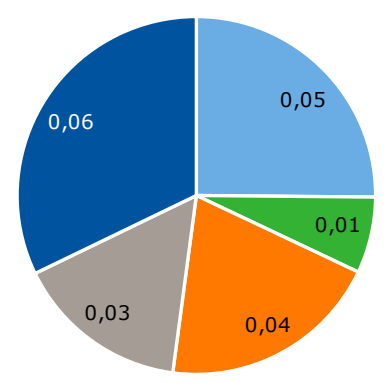

- Plant material - Boat lease $=$ Labour $=$ Capital goods - Other costs

Figure 4a

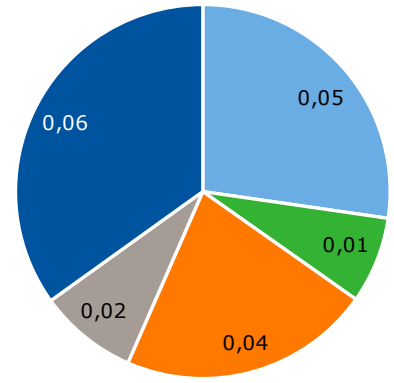

- Plant material - Boat lease $=$ Labour $=$ Capital goods $=$ Other costs

Figure 4 Breakdown of costs in multidimensional scenario

\subsection{Likelihood of future costs of seaweed production}

In table 2 a future scenario was defined, based on significant (but not the most drastic) reductions in the production costs. The results of the Monte Carlo analysis (see figure 5) illustrate how likely it is that the cost of seaweed production will fall within a particular range. For example, the figure shows there is a $5.2 \%$ chance that the cost price is between $€ 0.25$ and $€ 0.30$ per $\mathrm{kg}$ FW.

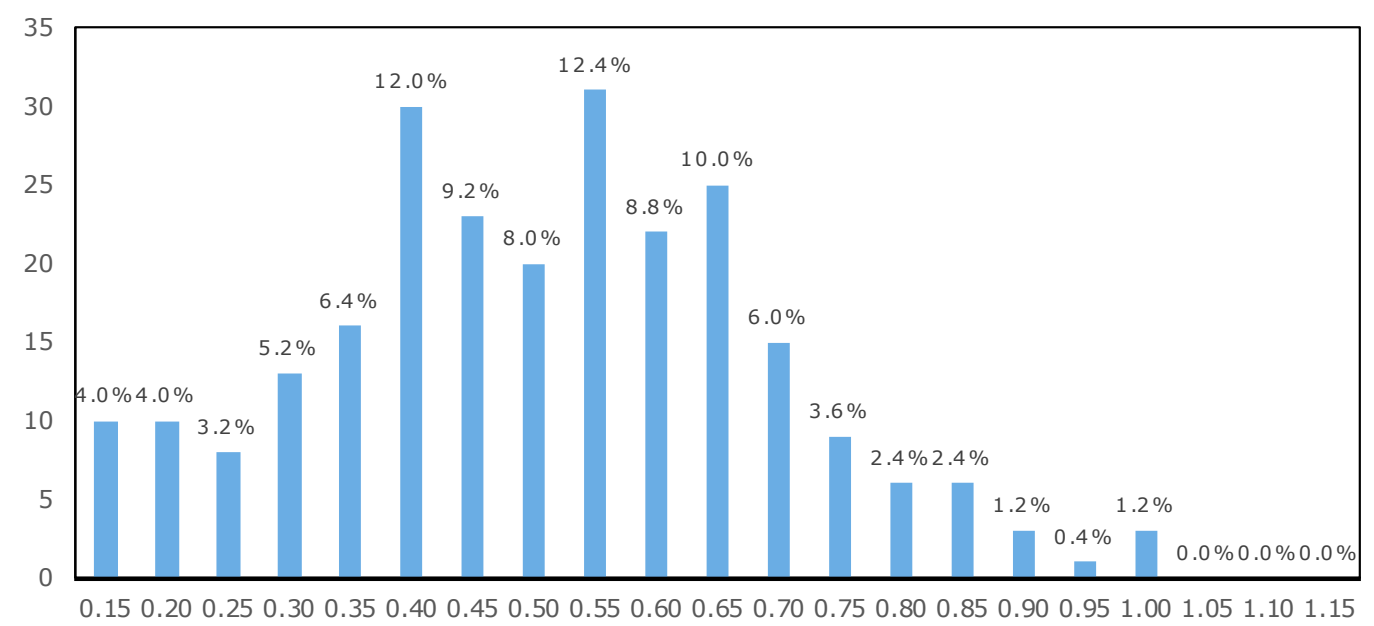

Figure 5 Results of Monte Carlo analysis

Figure 5 shows that cost price is likely to be in the range of $€ 0.30-0.70$ per $\mathrm{kg} F \mathrm{~F}$. In $73.4 \%$ of the 1,000 calculations, the cost price was within this range. 


\section{$4 \quad$ Reflection on the World Bank report}

\subsection{A skewed comparison with other countries}

One of the persistent questions during discussions on the economic feasibility of seaweed cultivation is how the envisioned North Sea production would compare to current production processes in other regions of the world. Here, a recent World Bank report (Bjerregaard et al. 2016) is illustrative. Two enterprise budgets in the report are presented here for comparison with the results of this study.

Table 4 Enterprise budget for Kappaphycus seaweed farming

\begin{tabular}{lll} 
Country & Indonesia & Mexico \\
\hline Species & Kappaphycus & Kappaphycus \\
\hline Production parameters & 30,000 & 10,000 \\
\hline - Total length of lines (m) & 8 & 4 \\
\hline - Number of cycles per year & 33,000 & 53,778 \\
\hline - Annual yield of dry seaweed (kg) & 0.85 & 1.00 \\
\hline - Farm gate price (US\$/kg) & & 13,264 \\
\hline Variable costs (US\$) & 0 & $\mathrm{n} / \mathrm{a}$ \\
\hline - Propagules & 29 & $\mathrm{n} / \mathrm{a}$ \\
\hline - Fuel & 420 & 7,115 \\
\hline - Maintenance and repair & 600 & 29,232 \\
\hline - Sales and Marketing & 5,369 & 6,043 \\
\hline Total variable costs (US\$) & 3,521 & 35,275 \\
\hline Total fixed costs (US\$) & 8,890 & 18,503 \\
\hline Total costs (US\$) & 19,160 & 0.66 \\
\hline Net returns (US\$) & 0.27 & \\
\hline Production costs (US\$/kg) & & \\
\hline
\end{tabular}

Comparing these enterprise budgets with the results presented above leads to a number of observations:

- The expected production costs per kg seaweed in the North Sea are slightly higher than the production costs in Mexico, but various options for cost price reductions are available. Based on the calculation provided in section 3, a reduction in costs or increases in yields could result in similar production costs. Production costs in Indonesia are significantly lower and not easily realised in North Sea seaweed farming.

- The cost of seeded line/propagules is very high in the North Sea case. Seaweed farmers in Indonesia prepare their own seeded line and thus incur no material costs for this.

- In both Indonesia and Mexico, the yield is relatively low compared to the expected yield in the North Sea. For Mexico, an annual yield of $5.3 \mathrm{~kg}$ dry seaweed per $\mathrm{m}$ of longline is reported, based on 4 cycles per year. This equals $1.35 \mathrm{~kg}$ of dry seaweed per $\mathrm{m}$ per cycle.

- The low yields per $\mathrm{m}$ are compensated for by the possibility to have multiple harvests per year; up to 8 cycles per year are reported in Indonesia. This will not be possible with the North Sea production system modelled in this report. 


\subsection{Reflection from a food systems perspective}

So far the analysis in this article has focused on the costs of seaweed production. The analysis shows that production costs are higher in the North Sea production system compared to production systems in tropical developing countries. Several ways to reduce costs were described in section 3.

Until now, there is little insight into what the growth of seaweed production will mean for the other links in the chain (e.g. processing, transport and sales, consumption) and what effects this will have on, for example, environmental aspects, added value and employment. A research approach that lends itself well to this 'broader view' is the so-called food system approach.

The food system approach describes the different elements of our food system and the relationships between those elements. It focuses on all activities related to the production, processing, distribution and consumption of food and also looks at the outcomes of these activities in terms of food security (food utilisation, food access and food availability), socioeconomic parameters (income, employment) and environmental issues (biodiversity, climate). The approach originates from the debate on food security at the beginning of this century, which has shifted the focus away from solely the production and availability of food to the access to and use of food, and pays attention to the different functions of food, the role of institutions and possible trade-offs (e.g. increased production vs the sustainable use of limited natural resources) (Ericksen 2007). Figure 6 shows a graphic representation of the food system approach.

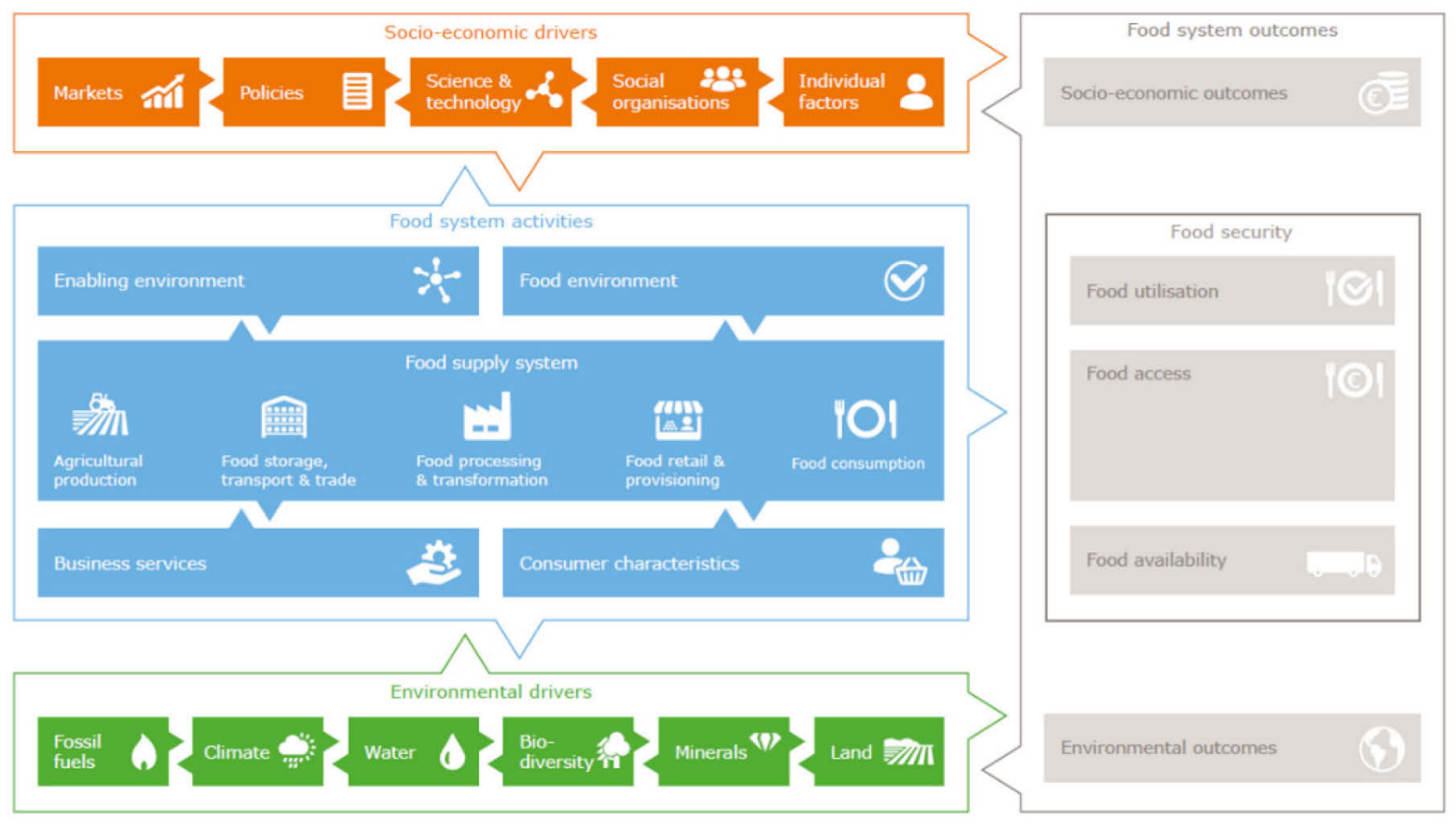

Figure 6 Graphic presentation of the food system approach (van Berkum \& Dengerink, 2017)

Adopting this wider perspective would add to the current analysis of the potential upscaling of production in the North Sea area. Shifting the focus from the costs of seaweed production and possible ways to decrease these, would allow for an analysis of the possible challenges one is likely to encounter further upstream in the value chain.

Upscaling seaweed production raises important questions with regard to the activities related to the processing, storage, distribution and consumption of seaweed. If production in the North Sea area is increased, what would be needed to store the produce and to process it? Is there enough demand from the market, be it the food, feed or pharmaceutical market? What are the possible effects on the 
other food and feed components that seaweed might replace? These and other questions would come to the fore.

Adopting this wider perspective also allows for assessing whether the business environment can enable the upscaling of production, looking at aspects like clear regulations, institutional arrangements, the research infrastructure, financial services, etc.

Finally, adopting this wider perspective may also shed a more nuanced light on the competitive position of seaweed production in northwest Europe compared to that in tropical developing countries, as the business environment in these countries may be less advanced. According to the World Bank Group article, "The growth of sea weed farming is constrained primarily by a lack of proper marine spatial plans and appropriate financing mechanisms secured with legal user rights" (Bjerregaard et al. 2016, pp. 9 and 12). 


\section{$5 \quad$ Conclusions}

The analysis presented above resulted in a number of expected cost prices of seaweed. Following the format in the model used, these are presented in $€$ per $\mathrm{kg} \mathrm{FW}$. Table 5 below summarises the results and recalculates the costs to the cost price per ton DM.

Table 5 Summary of results

\begin{tabular}{|c|c|c|c|}
\hline & Change foreseen & $\begin{array}{l}\text { Cost price seaweed } \\
(\mathrm{C} \text { kg FW) }\end{array}$ & $\begin{array}{l}\text { Cost price per ton }{ }^{3} \\
\text { ( } € \text { ton DM) }\end{array}$ \\
\hline Base case & & 0.78 & 5,200 \\
\hline \multirow{2}{*}{ One-dimensional } & Reduce costs of plant material & $0.38-0.78$ & $2,533-5,200$ \\
\hline & Increasing yield & $0.29-0.78$ & $1,933-5,200$ \\
\hline \multirow{2}{*}{ Multidimensional } & Combined use & 0.75 & 5,000 \\
\hline & $\begin{array}{l}\text { Combined use, reduced cost of } \\
\text { boat hire and plant material and } \\
\text { increased yield }\end{array}$ & 0.18 & 1,200 \\
\hline
\end{tabular}

\subsection{Indications for future research on and development of seaweed cultivation}

Based on the findings, we conclude that a significant cost reduction seems possible, with expected cost prices down to $€ 1,200$ per ton DM. If all goes well, relatively low-value markets such as the alginate market are within reach, with reported values of raw material of US\$950 per ton (Nayar and Bott 2014).

More realistically, a mix of low- and medium-value markets is needed to cover the costs of seaweed production in the North Sea. Current developments show that these markets exist; especially in the food market where seaweeds can be promoted as organic, sustainable and fair trade (Buschmann et al. 2017). The food market clearly comes with a number of challenges regarding secure and safe production and supply, however, and high certification demand. Yet from a cost price perspective, these markets seem within reach.

Pharmaceutical applications of seaweed are anecdotally reported and typically come with very high value per unit of seaweed. Given the uncertainty about actual demand, it is best to consider these as a possible bonus, but they should not be necessary to achieve economic feasibility.

Small-scale offshore production of seaweed is expensive. This should not come as a surprise. Significant reductions in the production cost are possible. Based on the analysis in this study, the following two priorities for research and development are formulated:

1. Reducing the cost of plant material

2. Increasing yields

Other improvements such as upscaling, lower cost of boat hire and combined use of the facilities also result in lower production costs, but this effect is much weaker.

\footnotetext{
${ }^{3}$ Assuming $15 \%$ dry weight.
} 
One possibility to reduce production costs is to have multiple harvests per year (this was not modelled). For the North Sea, this would require the development of a production system based on combining multiple species to achieve year-round production. Further research and development is needed to realise such a production system.

\subsection{Improving economic models for seaweed cultivation}

The model used in this study is limited to the production costs. Empirical evidence can be used to further validate the model for North Sea conditions. To gain a better understanding of the expected economic performance of seaweed value chains, the model should be extended to include processing and final products. The interlinkages between production and processing (e.g. due to varying contents over the year) should be included in such as model.

The social and ecosystem benefits of seaweed cultivation are often discussed. Seaweed cultivation could contribute to the strengthening of coastal economies, provide jobs, and reduce dependence on food and feed imports. It is also believed to benefit the local ecosystem, creating habitats and nursery areas that strengthen marine biodiversity (Hasselström et al. 2018; Elizondo-González et al. 2018). These effects are not quantified in this analysis but methods for quantification do exist.

Finally, the base case in this study consists of relatively large-scale seaweed cultivation (i.e. 1,000 production units), compared to current production volumes. The question is not only how profitable seaweed cultivation will be in the future, but also how the transition from current production volumes to this expected future volume can be realised and financed. 


\section{References and websites}

Bak, Urd Grandorf, 2018. "Production Method and Cost of Commercial-Scale Offshore Cultivation of Kelp in the Faroe Islands Using Multiple Partial Harvesting." Algal Research 33 (May). Elsevier: 36-47. doi:10.1016/j.algal.2018.05.001.

Berkum, S. \& J. Dengerink, 2017. De waarde van de voedselsysteembenadering voor de uitdagingen van de toekomst. Wageningen Economic Research.

Bjerregaard, Rasmus; Valderrama, Diego; Radulovich, Ricardo; Diana, James; Capron, Mark; Mckinnie, Cedric Amir; Cedric, Michael; Hopkins, Kevin; Yarish, Charles; Goudey, Clifford; Forster, John, 2016. Seaweed aquaculture for food security, income generation and environmental health in Tropical Developing Countries (English). Washington, D.C.: World Bank Group. http://documents.worldbank.org/curated/en/947831469090666344/Seaweed-aquaculture-forfood-security-income-generation-and-environmental-health-in-Tropical-Developing-Countries

Buschmann, Alejandro H., Carolina Camus, Javier Infante, Amir Neori, Álvaro Israel, María C. Hernández-González, Sandra V. Pereda, et al., 2017. "Seaweed Production: Overview of the Global State of Exploitation, Farming and Emerging Research Activity." European Journal of Phycology 52 (4). Taylor \& Francis: 391-406. doi:10.1080/09670262.2017.1365175.

Elizondo-González, Regina, Eduardo Quiroz-Guzmán, Cristina Escobedo-Fregoso, Paola MagallónServín, and Alberto Peña-Rodríguez, 2018. "Use of Seaweed Ulva Lactuca for Water Bioremediation and as Feed Additive for White Shrimp Litopenaeus Vannamei." doi: $10.7717 /$ peerj.4459.

Ericksen, P.J., 2007. "Conceptualizing food systems for global environmental change research". In: Global Environmental Change, 18(1), pp. 234-245

Hasselström, Linus, Wouter Visch, Fredrik Gröndahl, Göran M. Nylund, and Henrik Pavia, 2018. "The Impact of Seaweed Cultivation on Ecosystem Services - a Case Study from the West Coast of Sweden." Marine Pollution Bulletin 133 (October 2017). Elsevier: 53-64. doi:10.1016/j.marpolbul.2018.05.005.

Nayar, Sasi, and Kriston Bott, 2014. "Current Status of Global Cultivated Seaweed Production and Markets." World Aquaculture 45 (June 2014): 32-37.

van den Burg, S.W.K., P. Kamermans, M. Blanch, D. Pletsas, M. Poelman, K. Soma and G. Dalton, 2017. "Business Case for Mussel Aquaculture in Offshore Wind Farms in the North Sea." Marine Policy 85. doi:10.1016/j.marpol.2017.08.007.

van den Burg, S.W.K., A.P. van Duijn, H. Bartelings, M.M. van Krimpen and M. Poelman, 2016. "The Economic Feasibility of Seaweed Production in the North Sea." Aquaculture Economics and Management 20 (3). doi:10.1080/13657305.2016.1177859. 
Wageningen Economic Research P.O. Box 29703

2502 LS The Hague

The Netherlands

$\mathrm{T}+31(0) 703358330$

E communications.ssg@wur.nl

www.wur.eu/economic-research

Wageningen Economic Research MEMORANDUM

2019-012
The mission of Wageningen University \& Research is "To explore the potential of nature to improve the quality of life". Under the banner Wageningen University \& Research, Wageningen University and the specialised research institutes of the Wageningen Research Foundation have joined forces in contributing to finding solutions to important questions in the domain of healthy food and living environment. With its roughly 30 branches, 5,000 employees and 10,000 students, Wageningen University \& Research is one of the leading organisations in its domain. The unique Wageningen approach lies in its integrated approach to issues and the collaboration between different disciplines.

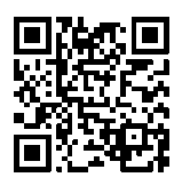





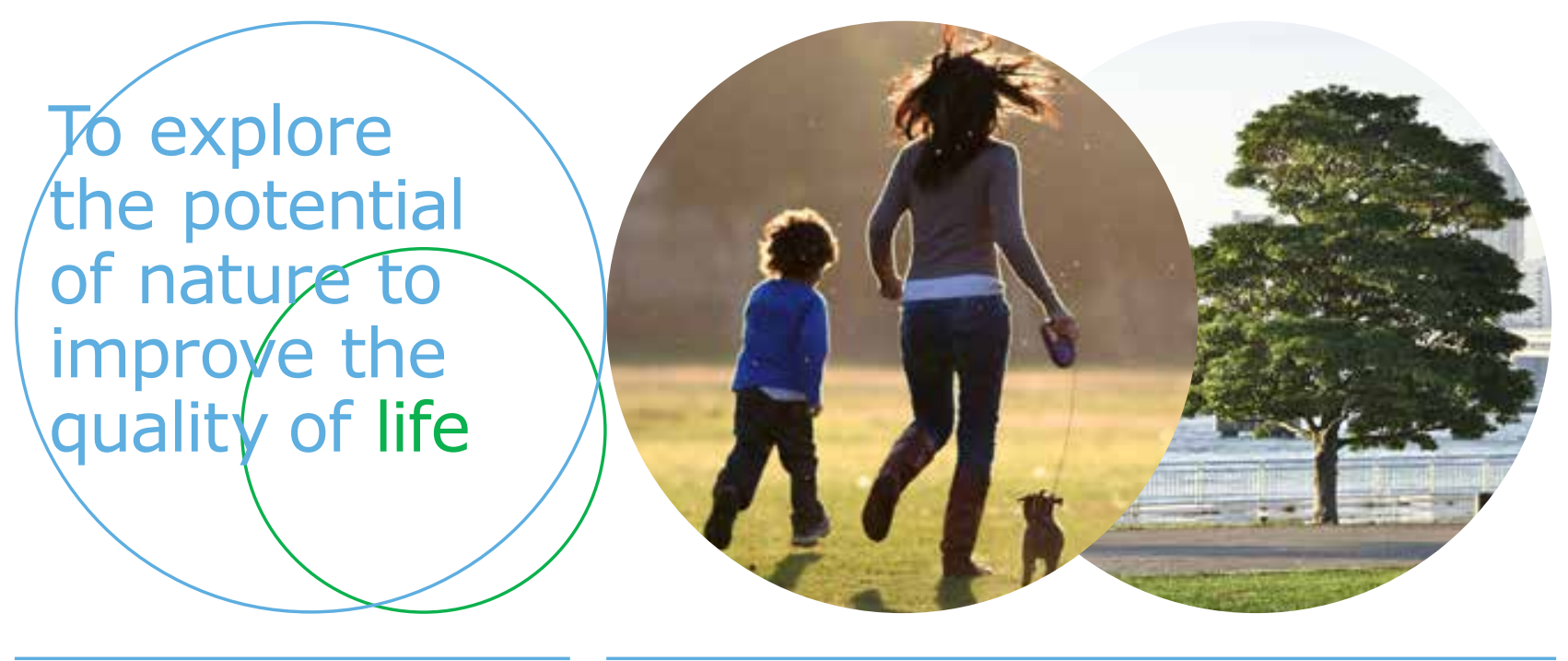

Wageningen Economic Research P.O. Box 29703

2502 LS Den Haag

The Netherlands

E communications.ssg@wur.nl

www.wur.eu/economic-research

Memorandum 2019-012
The mission of Wageningen University \& Research is "To explore the potential of nature to improve the quality of life". Under the banner Wageningen University \& Research, Wageningen University and the specialised research institutes of the Wageningen Research Foundation have joined forces in contributing to finding solutions to important questions in the domain of healthy food and living environment. With its roughly 30 branches, 5,000 employees and 10,000 students, Wageningen University \& Research is one of the leading organisations in its domain. The unique Wageningen approach lies in its integrated approach to issues and the collaboration between different disciplines. 